ISSN: 0210-7287

DOI: http://dx.doi.org/10.14201/161620199173195

\title{
LAS LENGUAS DEL EXILIO EN LAS LITERATURAS DE AL-ÁNDALUS
}

\section{The Languages of Exile in the Literatures of Al-Andalus}

\author{
TOmás ESPINO BARRERA \\ Universidad de Granada \\ tespino@ugr.es
}

Recibido: junio de 2019; Aceptado: septiembre de 2019; Publicado: diciembre de 2019

Ref. Bibl. TOMÁS ESPINO BARRERA. LAS LENGUAS DEL EXILIO EN LAS

LITERATURAS DE AL-ÁNDALUS. 1616: Anuario de Literatura Comparada, 9

(2019), 173-195

RESUMEN: El estudio del multilingüismo literario medieval se suele centrar en una concepción utilitaria de las lenguas, elegidas en función del género o el público, y con escaso valor de identificación de una comunidad política. En AlÁndalus, en cambio, la coexistencia de musulmanes, judíos y cristianos provocó que la cuestión de la lengua de escritura adquiriera un importante valor identitario. La lealtad a las lenguas sagradas de cada religión se tradujo en un discurso teórico y unas prácticas literarias muy diferentes del resto de Europa y marcadas por el exilio: un lamento elegíaco de la pérdida del latín, inquietud ante el riesgo de corrupción del árabe lejos de las grandes capitales de Oriente Medio y un esfuerzo por recuperar el hebreo bíblico como lengua poética.

Palabras clave: multilingüismo literario; lealtad lingüística; literatura hispanohebrea; literatura hispanoárabe; literatura mozárabe; literatura medieval.

ABSTRACT: The scholarship on medieval literary multilingualism is mostly focused on a utilitarian notion of language choice which only depends on genre 
or the type of audience. Languages in this context have little political value and do not necessarily identify a writer with a specific political community. In Al-Andalus, however, the coexistence of Muslims, Jews and Christians suffused the question of language choice with a strong sense of belonging. Loyalty to the sacred language of each religion was transposed to a series of deeply exilic theoretical discourses and literary practices which were very different from the utilitarian outlook of the rest of Europe: an elegiac lament for the loss of Latin, a deep concern about the purity of Arabic far from the great seats of learning in the Middle East, and the efforts of recovering Biblical Hebrew as a poetic language.

Keywords: Literary Multilingualism; Language Loyalty; Spanish-Hebrew Literature; Spanish-Arabic Literature; Mozarabic Literature; Medieval Literature.

\section{INTRODUCCIÓN}

La literatura escrita en una lengua distinta de la materna, prácticamente tan antigua como la literatura misma, ha pasado de ser un ámbito casi del todo ignorado a convertirse en un nuevo y pujante campo de estudio transdisciplinar. En constante movimiento entre (al menos dos) filologías, la literatura comparada, la traductología y la lingüística, el estudio de la literatura escrita en una lengua distinta de la materna se ha constituido como un campo en el que las aportaciones en forma de congresos, artículos, monografías y tesis doctorales han aumentado de manera notable en las últimas décadas. El multilingüismo literario medieval ocupa un lugar preeminente dentro de este panorama disciplinar. Aunque existen obras procedentes de la Antigüedad que mezclan diversos idiomas o están compuestas en una lengua distinta de la materna ${ }^{1}$, ningún otro período como la Edad Media estuvo tan marcado por las prácticas multilingües. En efecto, no solo la mayor parte de la producción escrita de la época se compuso en latín, una lengua que por aquel entonces era ya, tal como señalaría Dante en De vulgari eloquentia (I.i.3), una locutio secundaria en tanto que, al contrario que las lenguas vulgares, ya no se aprendía mediante imitación en la primera infancia, sino que buena parte de los poetas vernáculos elegían su lengua de escritura en función del género, el tema o el público de sus obras, independientemente del idioma hablado en su tierra de origen. A ello se suman no pocos autores que utilizaron el multilingüismo intratextual, es decir, la mezcla de diversos idiomas dentro de una misma obra, como una forma

1. Para un panorama de estas prácticas, especialmente presentes en Roma, véanse, por ejemplo, AdAMS (2003), SÁNCHEZ-OSTIZ et al. (2007) y TORRES GUERRA (2011). 
de caracterización de la pluralidad lingüística de la sociedad de su tiempo o como una manera de exhibir su virtuosismo lingüístico y poético. No es por tanto casual que uno de los primeros trabajos dedicados explícitamente al multilingüismo literario, el de Zumthor (1960), estuviera centrado precisamente al período medieval ${ }^{2}$.

Si bien el multilingüismo literario medieval, al menos en su vertiente vernácula, ha sido estudiado por Zumthor (1960), Forster (1970), Tavani (1981) y, ya en fechas más recientes, por, entre otros, Léglu (2010), Kleinhelz y Busby (2010), Classen (2013) o Gutiérrez García (2015), aún no se ha prestado suficiente atención a la especificidad de las prácticas multilingües en Al-Ándalus ${ }^{3}$, cuya lógica difiere radicalmente del multilingüismo practicado en el resto del continente europeo. El objetivo del presente trabajo consistirá, por tanto, en tratar de determinar cómo se desarrollan en Al-Ándalus un discurso propio y unas prácticas concretas en torno a la escritura en una lengua distinta de la materna, prestando especial atención a la dimensión exílica de las mismas y a su contraste con el multilingüismo característico de los reinos del norte.

En efecto, durante el período medieval, el occidente cristiano adoptó por lo general una concepción utilitaria de la lengua poética en la que el idioma de escritura podía elegirse como una herramienta en función de los objetivos que se deseaban alcanzar y no, tal y como quedó consagrado por la reflexión lingüística y literaria modernas, como la expresión natural e irremplazable de un pueblo. Por ejemplo, el catalán Ramón Vidal de Besalú (c. 1196-c. 1252) da en el prefacio a sus Rasos de trobar una serie de recomendaciones para orientar la elección de lengua según el tipo de composición: «La parladura francesca val mais et [es] plus avinenz a far romanz et pasturellas, mas cella de Lemosin val mais per far vers et cansons et serventes» (Vidal de Besalú 1972, 72-75). Como resume Léglu (2010, 5), hablando en su caso de la poesía provenzal, las lenguas eran «a lyric mode of expression that could be learned and adapted without the declaration of any political allegiance». Estas ideas se reflejaron en conocidos ejemplos de multilingüismo en el ámbito peninsular, como la decisión del rey de Castilla Alfonso X (1221-1284) de componer sus Cantigas de Santa María no en

2. El primer monográfico dedicado al multilingüismo literario, The Poet's Tongues, de Leonard FORSTER (1970) da comienzo con un capítulo dedicado a «Middle Ages and Renaissance", dejando de lado las importantes -aunque no tan numerosas como en la época medieval- prácticas multilingües de la Antigüedad clásica.

3. Las moaxajas y las jarchas, en cambio, sí han sido estudiadas en profundidad desde las primeras décadas del siglo Xx. El presente trabajo se centrará, sin embargo, en la defensa de la escritura literaria en lenguas sagradas (latín, árabe clásico, hebreo bíblico). 
castellano sino en una lengua con una tradición lírica de prestigio como el galaicoportugués o el ejercicio de virtuosismo plurilingüe de la Cobla en sis lengatges de Cerverí de Girona (1259-1285). En el contexto, además, de un mosaico dialectal en el que las lenguas vernáculas aún no estaban fijadas y carecían en su mayoría de modelos literarios, estas ideas y prácticas en torno a la elección de la lengua de escritura estaban en consonancia con una estructura política escasamente centralizada en la que las relaciones entre señores y siervos eran más importantes que una identidad comunitaria basada en una lengua común.

En las tierras conquistadas por los árabes en Al-Ándalus, en cambio, cristianos, musulmanes y judíos ofrecían sus particulares respuestas en lo que atañe a la cuestión de la lengua de escritura. El contacto entre religiones, culturas y lenguas tan diversas produjo una respuesta particular a la cuestión del multilingüismo literario en la que las lenguas sí poseían una importante valencia político-identitaria en un contexto de competencia religiosa. Por una parte, la conciencia del peligro de desaparición o degeneración de la lengua sagrada de cada pueblo (latín, árabe coránico, hebreo), que nunca coincidía plenamente con la lengua hablada, provocó la aparición de una insólita "lealtad lingüística» mediante la cual se trata de defender no tanto la lengua materna o una versión estándar de la misma -tal y como sucedería en Europa desde el comienzo de la modernidad a partir de las polémicas en torno a la Questione della lingua y, especialmente, a partir de las reivindicaciones nacional-lingüísticas de los románticos-, sino la lengua extinta de los libros sagrados. Por otra parte, como veremos, esta defensa de las lenguas muertas en Al-Ándalus se lleva a cabo en paralelo al desarrollo de una conciencia exílica de diversa índole: exilio con respecto a la comunidad basada en la Biblia y la literatura latina entre los cristianos, exilio con respecto a la pureza del pueblo y la lengua árabes entre los musulmanes, exilio con respecto a Jerusalén -pero también, paradójicamente, con respecto a los centros de la literatura árabe en Al-Ándalus- entre algunos judíos.

La aplicación de la noción de "lealtad lingüística» acuñada por Uriel Weinreich en la década de 1950 y que "como el nacionalismo, designa el estado mental en que la lengua (como la nacionalidad), en su calidad de entidad intacta y en contraposición a otras lenguas, ocupa una posición elevada en la escala de valores, posición que necesita ser "defendida" (Weinreich 1974, 209) plantea ciertos problemas, al igual que hablar de "nacionalismo" o "nacionalidad», en la época medieval. Frente a la ortodoxia modernista en los estudios acerca de las naciones y el nacionalismo -representada por Benedict Anderson y Eric Hobsbawm-, una serie de trabajos han puesto el acento en los orígenes premodernos de las naciones 
en forma de "etnias» (Smith 1986) e incluso llegan a hablar de «naciones antes del nacionalismo" (Armstrong 1982), si bien este tipo de reflexiones podrían representar más bien «metaphorical extrapolations of the concept of national identity par excellence: namely, modern national identity» (Domínguez 2018, 19). En todo caso, existe un consenso más o menos generalizado de que, en la cristiandad, las lenguas vernáculas se entendían generalmente como una marca fluida de la pertenencia a un grupo étnico determinado (Geary 1983, 20)4. Como hemos adelantado, la situación es distinta en Al-Ándalus, donde cristianos, judíos y musulmanes trataron de defender y cultivar sus respectivas lenguas sagradas en un esfuerzo por proteger su identidad cultural y religiosa ante la (real o percibida) agresión externa de las otras lenguas. A través del estudio de la movilización de la lealtad lingüística en Al-Ándalus no pretendemos inferir la existencia de supuestas naciones (cristianolatina, arabomusulmana o judeohebrea) en el sentido moderno, sino visibilizar ciertas prácticas y reflexiones en torno al multilingüismo que se diferencian claramente de la lógica imperante en el resto del continente europeo, así como destacar la dimensión exílica de la autopercepción cultural y lingüística de estos pueblos. Partiendo esencialmente de los estudios sociolingüísticos de Gallego (2003 y 2010) y de algunos textos fundamentales (religiosos, filosóficos, gramáticos y literarios) de la peculiar "cuestión de la lengua» en Al-Ándalus, trataremos de determinar cómo la singular situación política, religiosa y literaria andalusí define una situación en la que la lengua pasa a ser uno de los principales valores que tratan de preservar -O rescatar- pueblos enteros del exilio.

\section{LA LINGUA PROPRIA DEL EXILIO ENTRE LOS CRISTIANOS DE AL-ÁNDALUS}

La fulminante conquista musulmana en el año 711 se vio acompañada por un rápido cambio de lengua (del romance al árabe) en pocas generaciones. En la época de los mártires de Córdoba (850-859), los cristianos lamentan que sus jóvenes, seducidos por la elocuencia árabe, hayan descuidado "su propia lengua». Sin embargo, esta lengua "propia" no es el romance vernáculo sino el latín, lengua sagrada que se convierte así en el último bastión de la identidad cristiana frente al avance de la cultura islámica.

La situación lingüística de la península antes de la llegada de los musulmanes era similar a la de otras zonas de Europa occidental. La lengua

4. Los ejemplos anteriormente citados de Alfonso X y Cerverí de Girona dan prueba de la fluidez de los usos lingüísticos en el ámbito literario en los reinos cristianos peninsulares. 
romance se usaba para la comunicación oral mientras que el bajo latín seguía siendo la lengua escrita 5 . Lapesa $(1981,130)$ explica que, tras la rápida conquista árabe, los hispano-godos o "mozárabes" que permanecen en territorio musulmán conservan la lengua romance pero «escriben a veces en árabe y suelen tomar nombres árabes». San Eulogio de Córdoba (c. 800-859) ya advertía de la rapidez con que los cristianos adoptaron la lengua árabe en su obra hagiográfica Memoriale sanctorum. Uno de los principales datos que ofrece de algunos de los mártires cordobeses es su dominio de la lengua árabe: de san Isaac se nos dice que era "peritus et doctus lingua Arabica» (II.ii.1), mientras que tanto san Emilio como San Jeremías "Arabico insigniter praepolleba[n]t elloquio" (II.xii). De las palabras de san Eulogio podemos inferir además que el dominio de la lengua árabe por parte de los cristianos era considerado como una marca de distinción social que mejoraba sustancialmente las perspectivas en la Córdoba musulmana: precisamente por su dominio del árabe san Isaac había conseguido convertirse en consejero del mismísimo califa.

En torno a la misma época, Álvaro de Córdoba (807-861), poeta latino además de amigo y biógrafo de san Eulogio, lamenta la necesidad de adoptar las costumbres del Anticristo como la circuncisión o la prohibición de comer carne de cerdo y concluye su Indiculus luminosus con un conocido pasaje en el que deplora la pérdida de la lengua latina por parte de los jóvenes laicos cristianos así como su fascinación por la lengua y la literatura de los "caldeos», -es decir-, los árabes:

Quis, rogo, hodie solers in nostris fidelibus laycis inuenitur, qui scripturis sanctis intentus uolumina quorumcuumque doctorum Latine conscripta respiciat? Quis euangelio, quis prophetico, quis apostolico ustus tenetur amore? Nonne omnes iubenes $\mathrm{Xp}^{-}$iani uulto decori, lingue diserti, habitu gestuque conspicui, gentilici<a> eruditjoni preclari, Harabico eloquio sublimati, uolumina Caldaeorum hauidissime tractant, intentissime legunt, ardentissime disserunt, et ingenti studio congregantes lata constrictaque lingua laudando diuulgant, ecclesiasticam pulcritudinem ignorantes, et eclesiae flumina de paradiso manantja quasi vilissima contemnentes? $\mathrm{Heu}$, proh dolor, legem suam nesciunt $\mathrm{Xp}^{-}$iani et linguam propriam non advertunt Latini, ita ut omni $\mathrm{Xp}^{-} \mathrm{i}$ collegio uix inueniatur unus in milleno hominum numero qui salutatorias fratri possit ratjonauiliter dirigere litteras, et reperitur absque numero multiplices turbas qui erudite Caldaicas uerborum explicet pompas, ita ut metrice eruditjori ab ipsis gentibus carmine et sublimiori pulcritudine finales clausulas unius littere coartatjone

5. Sobre la situación lingüística en España durante la época visigoda, véase LAPESA (1981, 23-28). 
decorent, et iuxta quod lingue ipsius requirit idioma, que omnes uocales apices commata claudit [...]. Multa et alia erant que nostre huic expositjoni exiberent firmaitatem, immo que ipsam patule in lucen producerent $(\mathrm{xxxy})^{6}$.

Este lamento ante la extinción de la lengua de los cristianos revela la percepción del latín y de su literatura como parte integral de la identidad religiosa cristiana ${ }^{7}$. Álvaro de Córdoba no se refiere al romance vernáculo hablado habitualmente en su época -ignorado por completo en su texto-, sino a la lengua escrita, la lengua de la Iglesia y la lengua literaria en la que escribir cartas y poemas, que llega a calificar de lingua propria ${ }^{8}$. Aquellos que desconocen su "propia lengua», parece sugerir Álvaro, viven exiliados de su propio pueblo y de sí mismos.

Aunque el latín era una de las tres lenguas de la cruz, además de lengua litúrgica desde el siglo IV, su dimensión religiosa nunca llegó a ser tan importante como la del hebreo o la del árabe coránico, lo que podría explicar en parte la facilidad con la que los jóvenes cristianos adoptaron la lengua y la poesía de los árabes abandonando rápidamente el latín? . En todo caso, según podemos observar a tenor de las palabras de Álvaro, la

6. «Qué varón solícito se encuentra hoy entre los seglares, que dedicado a las Sagradas Escrituras, repase los volúmenes de cada uno de los doctores escritos en latín? ¿Quién se mantiene encendido por el amor al Evangelio, a las profecías y a los Apóstoles? ¿No es verdad que todos los jóvenes cristianos, de brillante presencia, elocuentes, distinguidos en sus gestos y vestimenta, sobresalientes en la sabiduría de los gentiles, notables por su conocimiento de la lengua arábiga, se cuidan con avidez de los libros de los caldeos, los leen atentísimamente, los discuten ardorosamente y reuniéndolos con gran afán, los divulgan con lengua profusa y afianzada, ignorando en cambio la pulcritud de la lengua de la Iglesia y despreciando por muy viles las fuentes que manan del paraíso. ¡Ay dolor! Los cristianos desconocen su propia ley y los latinos no entienden su lengua propia, en tal forma que apenas en toda la comunidad cristiana se encuentra uno de mil hombres, que pueda dirigir a un hermano una carta en latín correctamente y se hallan innumerables multitudes que son capaces de explicar las ampulosidades verbales de los árabes, hasta el extremo que, más eruditos en la métrica que esas mismas gentes y con más sublime belleza, adornan las cláusulas finales con el acortamiento de una letra [...]. Muchas y otras cosas habría para proporcionar firmeza a este comentario nuestro y que mostrarían la luz de un modo manifiesto" (traducción de Feliciano Delgado León).

7. Sin embargo, el propio Álvaro no era ajeno al proceso de obsolescencia de esta lengua, ya que, como señala Juan GIL (1971), su dominio de la morfología dejaba bastante que desear.

8. Según sugiere GAllego $(2003,136)$, el romance mozárabe, sin tradición ni prestigio como lengua escrita, no tenía ningún futuro ante el poderío literario del árabe clásico.

9. En todo caso, el afán de los cristianos por componer poesía en árabe no parece haber sido tan intenso como parecía indicar Álvaro de Córdoba, puesto que según GALLEGo 
identificación entre lengua latina e identidad cristiana fue mucho más potente en la Córdoba de los mártires, es decir, en una situación de intenso conflicto religioso.

No todos los contactos entre cristianos y árabes fueron plasmados literariamente en términos tan nefastos. De los contactos entre el árabe, el hebreo y el romance surgen, a partir del siglo $\mathrm{x}$, algunas de las primeras composiciones multilingües de la Europa medieval, las denominadas muwašs̆aha o moaxajas, composiciones árabes o hebreas terminadas en una estrofa en romance, llamada zarğa o jarcha (Lapesa 1981, 193), a las que habría que sumar, ya en territorio cristiano, las pocas palabras en árabe que le responde la mora a Trotaconventos en el Libro de buen amor (15091512), así como algunas frases en esta misma lengua en El conde Lucanor $(\mathrm{XLI}, \mathrm{XLVII})^{10} \mathrm{y}$, ya en el siglo XV, una curiosa exclamación pronunciada en árabe por la reina Catalina de Lancaster en el Cancionero de Baena, junto a otras en latín e inglés, su lengua materna, durante el parto del futuro rey Juan II:

En boses mas baxas le oy decir:

«Salue, Regina! ¡Saluadme, Señora!»

E a las de vezes me paresçie oyr:

"Mod hed god hep, alumbradm'agora".

E a guise de dueña que deuota ora:

"Quam bonus Deus!", le oy rezar,

E oyle a manera de apiadar:

"Çayha bical habin al cabila mora» $\left(226\right.$, v. 2) ${ }^{11}$.

En todo caso, estos casos de multilingüismo que combinan el árabe con el romance carecen de la fuerte dimensión identitaria del texto latino de Álvaro de Córdoba, y obedecen más bien a los patrones de fluidez lingüística observados en los reinos cristianos medievales y a un evidente ánimo de caracterización social combinado con cierto espíritu cómico. Como señala Hanlon (1997), la distribución idiomática de las moaxajas refleja una distinción temática que apunta a las condiciones sociolingüísticas de la época: la estrofa final, de tono lúdico u obsceno, se deja en manos del romance, lengua de escaso prestigio cultural en Al-Ándalus.

(2003, 136), solo se conservan las obras de dos escritores cristianos en lengua árabe: Ibn al-Mir'izì y and Abu al-Qāsim ibn Khayyāt, ambos del siglo XI.

10. Sobre el árabe en El conde Lucanor, véase NYKL (1942).

11. Sobre el árabe en el Cancionero de Baena, remito a ENTWISTLE (1937), NYKL (1938) у КrotKoff (1974), que, tras una larga disquisición, concluye que la última frase, que mezcla el árabe con el castellano, significa «ila parturienta te llama, matrona mora!». 
Pese a los esfuerzos de Álvaro de Córdoba por recuperar el latín entre los mozárabes, los cristianos acabaron por adoptar por completo esta lengua y, en algunos casos, la mantuvieron incluso después de la reconquista cristiana. Ignacio Ferrando (2000) señala las razones por las cuales una serie de documentos legales escritos en árabe en Toledo entre los siglos XII y XIII, es decir, dos siglos después de la reconquista cristiana (1085), utilizaban el árabe y no el romance o el latín. Por una parte, el romance aún no había alcanzado suficiente prestigio como lengua de la cultura y la administración para sustituir al árabe, mientras que el latín seguía perdiendo influencia. Por otra parte, Toledo había acogido sucesivas oleadas de refugiados cristianos recién llegados del territorio almohade. Por último, el árabe servía como marca de identidad mozárabe frente a los demás cristianos de la ciudad. Podría decirse por tanto que, una vez asimilados a la lengua árabe, los mozárabes conservarían la que se había convertido en su lengua materna incluso generaciones después de asentarse en territorio cristiano, es decir, incluso después de su "retorno" del exilio en territorio musulmán, o más bien tras «exiliarse» en territorio romance.

\section{3. "LEJOS DE LAS MEJORES NACIONES». LENGUA Y EXILIO ENTRE LOS MUSULMANES DE AL-ÁNDALUS}

El incontestable dominio del árabe como idioma de prestigio religioso, administrativo y literario en Al-Ándalus trae consigo una serie de discursos que proclaman su superioridad y lo consagran como piedra angular de la identidad musulmana. Pese a ello, tanto la situación diglósica del árabe como el contacto con otras lenguas (especialmente el romance) movilizan la lealtad lingüística hacia el árabe clásico, alertando del peligro de su corrupción y lamentando la lejanía de Al-Ándalus con respecto a las principales capitales religiosas y culturales del mundo musulmán. De este modo, el discurso de defensa de la pureza del árabe se torna en un lamento por el exilio al que se ve sometida esta lengua en Al-Ándalus.

Aunque, tal y como indica Wasserstein (1991, 4), el número de hablantes nativos de árabe que participó en la conquista musulmana y se estableció en la península en los años posteriores parece haber sido, en comparación con el número de hablantes bereberes, muy limitado, al cabo de pocos siglos el árabe se consolidó como la lengua principal de Al-Ándalus. Sin embargo y según explica Gallego (2010), la situación del árabe en Al-Ándalus estuvo, al igual que en el resto de zonas del mundo donde se ha hablado esta lengua hasta hoy, profundamente marcada por la diglosia entre árabe clásico y árabe dialectal. Por una parte, el árabe clásico gozaba 
de un inmenso prestigio religioso y cultural por ser la lengua de Mahoma y la lengua en que Alá transmitió su mensaje. De este modo, la lengua del Corán se convirtió en la guía literaria y estilística por excelencia para los musulmanes árabes, fundamentando en gran parte el discurso de la 'arabiya que, como explica Alony $(1995,17-26)^{12}$, defendía la superioridad del pueblo árabe sobre todos los demás en cuanto a linaje, libro sagrado, poesía e idioma ${ }^{13}$. Sin embargo, la pronunciada divergencia del árabe coránico con respecto al árabe coloquial hizo indispensable un costoso aprendizaje formal, fomentó la aparición de gran cantidad de obras dedicadas al estudio de su gramática y confirió un enorme prestigio social a aquellos que lograban dominar su estilo (Gallego 2003, 122-23) ${ }^{14}$. En literatura, la lengua poética por excelencia era este mismo árabe clásico, aunque se han conservado también colecciones de proverbios y de poesía popular (especialmente moaxajas y zéjeles) en el dialecto andalusí (Rubiera Mata 1992, 38).

La lealtad lingüística al árabe como lengua religiosa se pone de relieve, además de en la preferencia por su variedad clásica frente a su variedad andalusí, sobre todo en la inquietud que provocaba el contacto con las lenguas romances de los reinos cristianos del norte de la península. En efecto, existía la percepción de que el árabe puro estaba en peligro y necesitaba ser defendido especialmente de la nefasta influencia de las esclavas cristianas que criaban a los hijos de los potentados andalusíes. En tonos marcados no solo por la 'arabiya sino también por el exilio' ${ }^{15}$, el visir de Toledo Abu l-Mutarrif ibn Mutanna (s. XI) lamenta el "hablar dificultoso» de su tierra, debido, a su entender, tanto a la lejanía geográfica con respecto a las «mejores naciones» como a la costumbre de utilizar como amas de cría a esclavas que hablan romance: «iNo es verdad que desde que empieza a oír uno de los hijos de nuestra nobleza [...] no oye más que las palabras de una vil esclava, necia, que no sabe hablar el árabe?» (citado en Lapiedra Gutiérrez 1997, 275). Según

12. Sobre las implicaciones políticas de la 'arabiya, véase WAHNÓN $(2009,101)$.

13. Además de utilizar el argumento religioso, los defensores de la 'arabiya justificaban la superioridad del Corán por razones intrínsecamente lingüísticas: riqueza léxica, abundancia de metáforas, belleza fonética y estructura lógica (ALONY 1995, 22-24).

14. Para una serie de anécdotas en las que los gramáticos andalusíes corrigen, con evidente orgullo, los fallos gramaticales de los árabes, vid. GALLEGO (2003, 123-25). Para un estudio de la emulación poética andalusí con respecto a sus modelos árabes, véase Terés (1956).

15. En la Edad Media, el lamento por la tierra natal perdida es constante en la poesía árabe dando lugar incluso a una tradición y un género propios, desde la nostalgia de Abderramán I por Damasco al contemplar una palmera hasta las elegías por las ciudades caídas (Badajoz, Córdoba, Valencia, Sevilla, Granada) a medida que avanza la Reconquista. Sobre el tema del exilio en la poesía hispano-árabe vid. Dadour (1993) y ELInson (2009). 
ibn Mutanna, los bebés que se habían criado con estas mujeres tenderían necesariamente, una vez convertidos en hombres, a estar en contacto con los reinos cristianos, "conservar su idioma» $\mathrm{y}$ "tolerar sus costumbres». La lengua de la nodriza contribuye de este modo a crear peligrosos lazos afectivos con los rivales políticos y religiosos, socavando la autoridad de la lengua y de las leyes del profeta ${ }^{16}$.

En todo caso, incluso cuando el movimiento de la Shu'übiyya cuestiona la hegemonía política árabe con respecto a las poblaciones bereberes y autóctonas, como en la Risāla del escritor musulmán de origen vasco Ibn García (s. XI), no se ataca a la lengua árabe, que sigue siendo considerada la más perfecta en virtud de su importancia religiosa, sino que meramente se pide perdón por los posibles errores que los andalusíes pudieran cometer en ella. Para los no árabes, la lengua constituía pues, gracias a su enorme valor religioso, un factor de unión supraétnica por encima de cualquier consideración política ${ }^{17}$.

Por otra parte, resulta esclarecedor que en las airadas respuestas a la Risāla por parte de los árabes la lengua figure como el mayor de los dones otorgados liberalmente a los pueblos inferiores. En un comentario que podría servir de ilustración para la vertiente lingüística de la 'arabiya, Abu Yahya ibn Mas'ada, en su refutación de Ibn García, acusa de ingratos a aquellos que hasta que no empezaron a chapurrear el árabe no pudieron ni pensar ni expresarse debido al primitivismo de sus antiguas lenguas:

¡Fue en la lengua de los árabes, oh prisioneros, en la que adquiristeis la sabiduría! [...] Farfullabais en la lengua árabe pero detestabais el saber de los árabes; entonabais su grito de guerra, imitabais sus poemas y rebuznabais entre sus asnos, pero vuestra marca no es como la suya. ¿Acaso no perfeccionasteis vuestra inteligencia tras hablar en vuestra lengua defectuosa y en un tartamudeo extranjero? [...] ¿Acaso tuvisteis tú y tus ancestros, oh villano que has escapado del castigo que mereces, una lengua en la que hablar [...], una gramática digna de ser mencionada por nosotros, o un balbuceo con inflexiones y declinaciones en vuestra previa condición? (Monroe 1970, 32-33; la traducción es mía).

16. Nótese, además, que la palabra utilizada para hacer referencia a la lengua romance ('ajamì) era también utilizada en Al-Ándalus como sinónimo de "cristiano" (GALLEGO 2010, 359-60).

17. Sobre la Shu'übiyya en Al-Ándalus y la obra de Ibn García y sus refutaciones vid. Monroe (1970), en especial las páginas 29-33 para el debate lingüístico, así como Gallego (2003, 134-35; 2010, 358). 
Tras la reconquista, según explica Gallego (2003, 114-116), los musulmanes que permanecieron en territorio cristiano, los llamados "moriscos", tuvieron inicialmente garantizado su derecho a conservar su religión, sus instituciones jurídicas y su lengua, pero se vieron posteriormente sometidos a una creciente presión asimilatoria por parte de los cristianos. Mientras que la gran mayoría acabó adoptando la lengua romance -conservando en muchos casos, eso sí, el alfabeto árabe en su forma aljamiada como último vestigio de la lealtad lingüística a la lengua sagrada-, los moriscos de Valencia conservaron celosamente el uso oral de la lengua árabe hasta su expulsión definitiva en 1609, concluyendo así la trayectoria exílica de este idioma en la península ibérica.

4. «LA LENGUA SANTA DEL PUEBLO DISPERSO». LENGUA Y EXILIO ENTRE LOS JUDÍOS DE AL-ÁNDALUS

Los judíos, pueblo diaspórico por excelencia, viven en Al-Ándalus una multiplicidad de exilios que se superponen unos a otros: exilio religioso, político, metafísico, cultural y, sobre todo, lingüístico. A través de un singular proyecto de recuperación de su lengua sagrada con el fin de darle nueva vida en una nueva literatura que combina influencias bíblicas y árabes, los judíos construyen una compleja identidad cultural y política con la que lamentan y al mismo tiempo tratan de remediar sus múltiples exilios.

Al menos desde la época del exilio en Babilonia, el pueblo judío se ha caracterizado por su multilingüismo y por utilizar, a menudo modificándola, la lengua dominante en los territorios donde se asentaban. Según señala Wahnón, tras la llegada de los árabes, las comunidades judías que se encontraban viviendo en la península desde la época de la diáspora adoptaron la lengua de los nuevos conquistadores, «haciéndola suya al usarla durante siglos no sólo para la comunicación cotidiana sino también para la científica y religiosa" $(2009,100)$, si bien utilizaron para este tipo de escritos el «udeo-árabe», un registro dialectal, lleno de citas y vocabulario bíblico y escrito en el alefato o alfabeto hebreo ${ }^{18}$. El alcance de la preponderancia del árabe llegó incluso, según explica Nehemías Alony (1995, 13), al campo de la Biblia y el Talmud, como demuestra el hecho de que la Guía de perplejos de Maimónides se escribiera en esta lengua y no en hebreo.

Gallego (2003, 116-117) indica que el dominio de la lengua árabe por parte de los judíos les sirvió asimismo para conseguir ascender a

18. Sobre el judeo-árabe, véase GALLEGO (2006). 
importantes puestos de responsabilidad y desempeñar un papel clave en la traducción y transmisión de la sabiduría árabe en los reinos cristianos, en los que floreció además una literatura escrita en lengua romance con caracteres hebreos e influenciada por la gramática y el vocabulario hebreos. Por otra parte, la dimensión cristiana del latín desempeñó paradójicamente un papel decisivo en la expansión de la lengua castellana gracias a la intervención de los traductores judíos. En efecto, tal y como señala Lapesa (1981, 237), los judíos activos en la Escuela de traductores de Toledo preferían traducir los textos árabes directamente al castellano, evitando así el latín y sus evidentes connotaciones cristianas.

El uso del judeo-árabe como lengua de producción de textos científicos e incluso teológicos por parte de la comunidad judía en Al-Ándalus contrasta con el insólito uso del hebreo bíblico como lengua literaria ${ }^{19}$. Tal y como recuerda Wahnón $(2009,100)$, «los grandes líricos hebreos del período -Yehudá ha-Levi, Mošeh Ibn Gabirol, Mošeh ibn 'Ezrá- [escribieron] siempre en hebreo y, por consiguiente, para lectores hebreos». La recuperación del hebreo ha de entenderse fundamentalmente desde la perspectiva exílica de la comunidad judía, indisociable de su situación religiosa, política y sociolingüística en Al-Ándalus. En la Edad Media, el exilio, expresado mediante el concepto hebreo de galut, abarcaba no solo la noción de la comunidad judía exiliada de Israel, sino que hacía también referencia a las condiciones de vida presentes de dicha comunidad. Según señala Cohen (2000), galut se entendía, además de en términos de exilio histórico con respecto a la tierra de Israel, como la marginación de la cultura y la sociedad mayoritarias en la época. Por último, tal y como señala Esperanza Alfonso $(2004,33)$, gran parte del pensamiento hebreo medieval, al igual que sucede en algunos autores cristianos del mismo período, está penetrado por teorías de corte neoplatónico según las cuales el alma en el cuerpo viviría una especie de destierro de su patria celeste. A estas acepciones colectivas y metafísicas del exilio habría que añadir una acepción de tipo individual, especialmente significativa durante los sucesivos períodos de inestabilidad política de Al-Ándalus tras el fin del califato y el tumultuoso período de los reinos de taifas y las invasiones almorávides y almohades: la del desplazado, voluntaria o involuntariamente, en busca de conocimiento,

19. El hebreo había dejado de hablarse en torno al año 200 d. C., aunque sobrevivió en cierta medida como lengua de culto. Si bien se conservan algunos ejemplos de uso literario del hebreo rabínico en los piyyutim o poemas litúrgicos compuestos en Palestina en torno al siglo vi d. C., el rescate del hebreo bíblico como lengua literaria en Al-Ándalus supone un hito en la historia de la literatura hebrea. Para la historia de la lengua hebrea, véase SÁENZ BADILLOS (1988). 
riqueza o libertad. El exilio múltiple de los judíos de Al-Ándalus es indisociable pues de sus particulares prácticas lingüísticas y literarias: la recuperación de la lengua sagrada puede así entenderse como un simulacro de retorno simultáneo a varios destinos (Israel, la patria celeste del alma, la tierra perdida en Al-Ándalus) a través de la poesía.

Sin embargo, la tarea de insuflar nueva vida poética a un idioma que llevaba más de mil años sin hablarse se presenta difícil y suscita desde el primer momento encarnizados debates entre los poetas y gramáticos hebreos. Los esfuerzos del poeta y lexicólogo Menahem ben Saruq (siglo x), autor de uno de los primeros diccionarios de hebreo bíblico, se ven atenazados por la feroz crítica del poeta nacido en Fez Dunash ben Labrat, a quien los discípulos de ben Saruq reprochan a su vez la aplicación, para ellos inadecuada, de la métrica árabe a la lengua hebrea. Estas disputas de carácter técnico acaban desembocando en una reflexión elegíaca acerca de la pérdida de la lengua del pueblo judío en el exilio:

Si no hubiésemos sido desterrados de nuestra tierra, dispondríamos de toda nuestra lengua, como antaño, cuando habitábamos seguros en parajes tranquilos. Sólo entonces conoceríamos todas las particularidades de nuestro idioma, todas sus acepciones, dominaríamos sus metros y fijaríamos sus fronteras. Pues la lengua de cada pueblo tiene su métrica y su gramática, sólo que la nuestra se ha perdido por la magnitud del pecado, se nos ha ocultado por la gran culpa desde el día que salimos en diáspora. Tras haber sido amplia, ha quedado mermada y escondida, vedada. Si no fuese porque Dios obró milagros, al contemplar la indigencia de su pueblo, se hubiese perdido y consumido incluso lo poco que queda (citado en Benavente 1986, 15).

La "Seguridad» y «tranquilidad» del pueblo judío en Israel se corresponden, según la opinión de los discípulos de ben Saruq, con la integridad de la lengua y la métrica hebrea, mientras que el exilio sería el causante de su olvido. La labor de estos estudiosos bíblicos será por tanto redescubrir y recomponer el hebreo, es decir, recuperar esta lengua del exilio en su máximo esplendor poético.

La recuperación y defensa de la lengua sagrada se convierte no solo en objeto de discusión teórica entre eruditos, sino en tema fundamental de algunas de las nuevas composiciones hebreas. De este modo, uno de los principales poetas de la generación que seguiría a Dunash y ben Saruq, el malagueño Shĕlomoh Ibn Gabirol (1021-1070), entremezcla poesía y reflexión lingüística en primera persona en su poema 'Anaq:

Habla Shělomoh el Sefardí, que /

ha recogido la lengua santa para el pueblo disperso.

Al ver mi corazón a la comunidad de la Roca, se dispuso / 
a instruir a ese resto suyo que sobrevive, dándose cuenta de que ha sido destruida su lengua / santa, y casi ha desaparecido.

Su lengua es extraña a la lengua hebrea y no / conoce la lengua judía.

La mitad habla en lengua cristiana, y la otra mitad / en la lengua de los hijos de Qedar, tan oscura (Sáenz Badillos 1980, vv. 4-8).

Tras describir en términos elegíacos la situación lingüística de los judíos que han olvidado su lengua en el exilio, Ibn Gabirol proclama la excelencia del hebreo sobre todas las demás lenguas: el hebreo es la lengua del cielo y fue la lengua común de la humanidad hasta la caída de la Torre de Babel, la lengua en la fueron escritas las Tablas de la Ley y la lengua en que hablaron los profetas (vv. 36-46). La primera parte del poema concluye con la exhortación «Sed fuertes y que no desfallezcan vuestras manos abandonándola, / pues no es cosa ligera, sino de gran valor» (v. 47) antes de dar paso a una disquisición (en verso) de la gramática hebrea.

¿Pero cómo sería posible reconstituir una lengua que llevaba sin hablarse más de mil años y cuyos principios métricos eran desconocidos? No todos los hebraístas sefardíes compartieron el celo de los discípulos de ben Saruq a la hora de separar lo hebreo de lo no hebreo. Mošeh ibn 'Ezrá (1055-1138), además de dominar el hebreo, la exégesis bíblica y la tradición rabínica, destacó, según Wahnón, por su profundo conocimiento de la gramática y la poética árabe y por su familiaridad con la filosofía griega. Su obra se entiende, por tanto, como un «esfuerzo [...] para conciliar las diversas tradiciones culturales y literarias de las que se sentía deudor» $(1998,160)$. Este proyecto de síntesis de diversas tradiciones favorece que ibn 'Ezrá se muestre especialmente sensible a la diversidad lingüistica. En su Kitab al-Muhadara wal-Mudakara, escrito en árabe, ibn 'Ezrá observa la influencia del clima y la geografía sobre las cualidades de los pueblos. De este modo, para el pensador andalusí los griegos estarían especialmente dotados para la filosofía, mientras que los «ismaelitas", es decir, los árabes, eran el pueblo de la elocuencia:

La habilidad en la expresión era connatural en ellos; hombres, mujeres, ancianos y niños, perturbados y necios, entre las masas populares y la gentecilla del desierto y entre los desechos de las poblaciones, (era como) un don otorgado por las estrellas, el temperamento propio de su región, del clima de su país y de sus aguas que secan la humedad de sus lenguas ('Ezrá 1986, 32-33).

Esta tesis revela la admiración de ibn 'Ezrá por la elocuencia árabe, que tratará de imitar en su justa medida -es decir, siempre teniendo en cuenta 
que «es imposible que los nombres, los recursos del habla y su bagaje sean idénticos en todas las lenguas» (23v.)- también en su producción literaria en hebreo: no en vano, según explica Wahnón (1995, 44) ibn 'Ezrá fue uno de los más entusiastas innovadores a la hora de incorporar elementos árabes en su poesía hebrea ${ }^{20}$. El debate, pues, estaba servido. En términos idénticos pero dando preferencia esta vez al pueblo judío, el también poeta e íntimo amigo de ibn 'Ezrá, Yehudá ha-Levi (c. 1070-1141), utiliza tal y como observa Katzew $(1984,182)$ el mismo método para otorgar un lugar privilegiado para el pueblo judío basándose en criterios climáticos: al estar situada en un punto intermedio entre Grecia y Arabia y gozar de un clima moderado, la tierra de Israel fue según él el lugar idóneo para el florecimiento de los profetas.

Mientras que ibn 'Ezrá, sin renegar en ningún momento de sus raíces hebreas, admira la cultura y la lengua árabe, ha-Levi proclama la superioridad abrumadora del pueblo judío en todos los aspectos, incluyendo, como señala Wahnón, $(2009,102)$, la lengua ${ }^{21}$. Significativamente, explica Katzew (1984, 183), ninguno de los dos vive en su clima ideal, puesto que ambos viven en el exilio. Sin embargo, mientras que para ha-Levi su único y doloroso exilio es haber nacido lejos de Jerusalén ${ }^{22}$, ibn 'Ezrá sufrió, además, dos exilios a lo largo de su vida: primeramente una especie de «exilio interior" cuando sus hermanos y amigos huyen de Granada tras la invasión almorávide y él queda atrapado en la ciudad ${ }^{23} \mathrm{y}$, posteriormente, su exilio definitivo de su ciudad natal desde 1095 hasta su muerte buscando refugio en la áspera Castilla, «un pueblo de labios balbucientes, de idioma incomprensible» (Brody núm. 145 vs. 6).

20. Para un análisis de la influencia árabe en la poesía hebrea de Al-Ándalus, vid. SCHIPPERS (1994).

21. En su Cuzary, escrito originalmente en árabe, HA-LEVI señala la indisoluble unión de los destinos del pueblo judío y el idioma hebreo al tiempo que proclama su superioridad sobre todas las demás lenguas: «Succediole lo que succedió a sus dueños: fue empobrescida con su pobreza y estrechada con su diminuicion; que ella por si es la mas excelente de las lenguas, como consta por tradición y por rason» (II. lxviii).

22. «Mi corazón está en Oriente y yo me hallo en el confín de Occidente. / ¿Cómo saborear los manjares y disfrutarlos? / ¿Cómo cumplir mis votos y mis promesas, si Sión está bajo el yugo cristiano y yo bajo el de los árabes? / Sería fácil para mí abandonar todo lo bueno de Sefarad, / y preciado contemplar las ruinas del Santuario destruido" (Orfali 1985, 189).

23. "Me quedé en Granada como extranjero residente en el país. [...] La huida me fue imposible» (Brody n. ${ }^{\circ}$ 263, líneas 41-48; citado en NAvarro Peiro 2001, 388). 
En el exilio, pues, la cuestión de la lengua vuelve al primer plano en la escenificación de la incomprensión de la lengua extranjera ${ }^{24}$, y, sobre todo, en el desarrollo de las ambivalentes imágenes de su poesía hebrea. Ibn 'Ezrá, tal y como indica Alfonso (2004, 41), identificó siempre Al-Ándalus en su poesía profana como su hogar, aunque no dejase nunca de añorar la tierra de Israel en sus poemas litúrgicos. Esta superposición del exilio individual de ibn 'Ezrá y el exilio del pueblo de Israel es especialmente visible en las imágenes del destierro tomadas de la Biblia, por ejemplo el Salmo 137 ("Junto a los ríos de Babilonia") en "Ad an be-galut", con las que describe su propio exilio de Granada, o en las descripciones bíblicas de Jerusalén aplicadas a la ciudad andaluza en este mismo poema o en «Ha-dami tidreshu». La identificación de Granada con las tierras bíblicas se extiende incluso a la utilización de topónimos como «Hadar Rimón» ( $c f r$. el topónimo bíblico "Hadad Rimón» en Zac 12:11) en referencia a la ciudad de Granada ${ }^{25}$ o "Senir", monte bíblico del Líbano en referencia al Sinnil, el nombre árabe del río Genil, cuyas aguas descienden de las montañas de Sierra Nevada (Navarro Peiro 2001, 385, n. 10 y 386, n. 11):

Si aún me devolviera Dios

A Granada [hadar Rimón], mis caminos prosperarían.

Con las aguas del Senir me embriagaría, aguas que se mantienen puras, aun cuando los torrentes más deliciosos bajen turbios (Brody n. ${ }^{\circ}$ 67, vv. 31-32, citado en Navarro Peiro 1995, 54).

El lamento por la lengua y la patria perdidas en el exilio, así como la exhortación al retorno a las mismas, abarcan todos los ámbitos de la literatura hebreoespañola: tratados teóricos, poesía y, por último, prosa literaria. $\mathrm{Al}$ igual que sucediera con los tratados (escritos en árabe) y gran parte de la poesía (en metros árabes), la prosa escrita por autores judíos hizo suyos géneros genuinamente árabes, como la macama. Este género de relatos cortos en prosa rimada, de lenguaje muy elaborado, acerca de todo tipo de temas tanto serios como cómicos dentro de un mismo marco y por lo general protagonizados por un héroe de tipo picaresco había sido cultivado en Oriente Medio desde el siglo $\mathrm{X}^{26}$. El hecho de que sea este género árabe el que Judá ben Shělomo Al-Harizi (1165-1225) utilice en su Sefer Tahkěmoní [Las asambleas de los sabios] para cantar las alabanzas de la lengua hebrea

24. Ibn 'Ezra tal vez estuviera exagerando o incluso fingiendo su incomprensión del idioma de Castilla, puesto que en su juventud había compuesto algunas moaxajas con jarchas romances, recogidas por SÁENZ BADILLOS (1990).

25. Rimón significa literalmente "granada" en hebreo.

26. Sobre la macama, véase HämEEN-ANTTILa (2002). 
revela la complejidad de la red de lealtades e influencias que configuran la literatura hebrea medieval.

En su obra, Al-Harizi combina simultáneamente la pasión del viaje constante y la nostalgia por Sión y por la tierra natal, así como la reivindicación de la lengua hebrea y la práctica del virtuosismo multilingüe más deslumbrante ${ }^{27}$, articulando de este modo una compleja tensión entre varias literaturas, varios exilios, varias lenguas y varios retornos superpuestos: no en vano, Tahkèmoní, que puede ser leído en cierto modo como un libro de viajes, fue compuesto durante uno de los largos periplos del autor. Impelido por su deseo de visitar Sión -«Emigró mi alma de España a Sión» afirma en esta misma obra (28.2)-, Al-Ḥarizi recorrió toda la península ibérica, el sur de Francia, Marruecos, Egipto, Siria, Palestina y Mesopotamia: «Me tomó la itinerancia sobre sus alas y me ató con las cuerdas de su compañía. Me llevó sobre los alones de la partida, me incitó a recorrer países, a girar por zonas habitadas, a medir tierras, a repasar valles. Un país me impelía a otro país (23.1)». A pesar de ello, el escritor sefardí sentía a menudo nostalgia de su tierra de origen, "la morada donde yo encontraba mi libertad" (38.1) y no dejó de proclamar su devoción por la lengua sagrada. Como él mismo explica en la macama introductoria, Al-Harizi compuso el libro "para mostrar la fuerza de la lengua santa al pueblo santo que se ha embadurnado sin que puedan ver sus ojos y entender sus pensamientos» (17). En términos similares a ibn Gabirol, Al-Harizi $(1988,11)$ explica el origen del libro narrando cómo el entendimiento se le aparece mientras duerme pidiéndole que defienda el hebreo:

[p]ara que sepan todos los pueblos de la tierra que la lengua santa es incomparable en la pureza de sus palabras y en la belleza de sus metáforas, porque es como una novia engalanada con todo su atuendo. La poesía es su manto y un perfume de mirra está en sus fimbrias. Cuando retira su velo, todos los ojos quedan pendidos de ella y todo corazón queda atado con sus cuerdas.

Imbuida de una virginal pureza exenta de contaminación con otros idiomas, agraciada por una extraordinaria belleza formal y arropada por una rica tradición literaria, la lengua hebrea se nos presenta como un fascinante objeto de deseo envuelto en el halo sagrado que preside la ceremonia de bodas. La comparación de la lengua hebrea con una hermosa

27. Es famoso su poema trilingüe en la macama 20 en el que cada uno de los tres hemistiquios de cada verso está escrito en un idioma diferente (hebreo, árabe y arameo) y rima con los demás. 
mujer continúa en las líneas siguientes, en las que Al-Harizi narra de forma alegórica la gloriosa historia del hebreo como lengua del pueblo elegido, su posterior extinción como lengua hablada y el "adulterio" que cometen los judíos al «besar el seno» de la lengua árabe:

Todos sus hijos abandonaron su lengua y se hicieron balbucientes. Su plata devino escoria. Ella llora amargamente durante todo el día y a las orejas herméticamente cerradas dirige las siguientes palabras: ¿Qué encontrasteis errado en mi obra que os habéis alejado de mí? ¿Acaso el día que habló el Señor con vuestros padres no estuve yo entre el Señor y vosotros? ¿Acaso las tablas de la alianza no fueron escritas con el aliento de mi boca y extraídas de la roca de mi lengua? Todo el tiempo que habitó la gloria de Dios en su templo, fui como una reina consorte que me sentaba a su vera, de modo de poder comunicaros su secreto y de extender sobre vosotros su gloria. Pero vuestros hijos me han despreciado y han abrazado la lengua de los extranjeros, me abandonaron y quemaron incienso a otros dioses. A la lengua de los israelitas la hicieron esclava de la lengua árabe. [...] Amaron a la mujer de los extranjeros, besaron su seno, porque las aguas robadas les fueron más dulces. Su corazón quedó seducido cuando vieron cuánta poesía preciosa dio a luz Agar la egipcia, la esclava de Sara, mientras que Sara estaba estéril (Al-Harizi 1988, 12).

Si bien las metáforas de Al-Ḥarizi no son del todo consistentes -los judíos se presentan a veces como hijos y a veces como maridos de la lengua hebrea-, su narración alegórica construye una imagen orgánica y afectiva, un retrato a la vez cercano y lleno de devoción religiosa de una lengua que es a la vez madre y esposa. A través de imágenes y referencias bíblicas que proclaman el papel fundamental de la lengua sagrada en la transmisión de la voluntad de Dios, presenta la extinción del hebreo como una traición a la esposa otorgada por Dios en favor de una fértil extranjera, la lengua árabe. El escritor sefardí concluye su relato introductorio celebrando su boda con la lengua hebrea -señalando pudorosamente que «sin relación sexual alguna" (13) - y concibiendo un hijo (el libro) con ella. De este modo, Al-Harizi se presenta implícitamente como un Abraham literario que, pese a sus escarceos con la literatura árabe, es esposo de la única lengua capaz de concebir en su vejez, convirtiéndose así en el patriarca que conducirá a su progenie literaria a la tierra de Canaán.

\section{CONCLUSIÓN}

La situación lingüística y literaria de Al-Ándalus constituye un caso excepcional dentro de la Europa medieval. Al contrario de lo que sucedía en 
otras partes del continente, las lenguas en Al-Ándalus no se percibían solo como herramientas que podían cambiarse fácilmente según el público, el género literario o la temática. Si bien el árabe era indudablemente la principal lengua de cultura -recuérdense los tratados filosóficos, gramáticos y poéticos hebreos escritos en este idioma-, otras dos lenguas sagradas como el latín y el hebreo disputaban su dominio al despertar el sentimiento de lealtad lingüística entre cristianos y judíos, respectivamente. De este modo, Álvaro de Córdoba lamenta que los cristianos dejen de leer sus libros sagrados y dejen de escribirse en latín, los árabes temen la corrupción de la lengua del Corán en contacto con los infieles, y los judíos se afanan por construir una literatura en una lengua que nadie hablaba desde hacía más de mil años. Al contrario de lo que sucederá a partir del surgimiento de los estados-nación, son lenguas muertas y sagradas y no lenguas vernáculas las que servían como seña de identidad de una comunidad. En este sentido, una mirada al discurso acerca de las lenguas en las literaturas de Al-Ándalus puede servir no para aplicar categorías nacional-literarias modernas a fenómenos premodernos, sino más bien para desvincular la noción de lealtad lingüística a conceptos relativamente recientes como "nacionalidad» $\mathrm{O}$ "nacionalismo».

El hecho de que la lealtad lingüística se aplique en este caso a lenguas que no eran habladas habitualmente puede explicarse por el contraste entre el caos lingüístico vernáculo en continua mutación -entendida normalmente como degeneración- frente a la estabilidad eterna del texto sagrado. En el Babel andalusí dominado por los árabes y la 'arabiya, el idioma se convierte en la posesión más preciada rescatada del exilio y en una suerte de intento por recomponer una totalidad coherente y estable formada por la tierra, la lengua y la religión de los ancestros. La escritura en latín, árabe clásico o hebreo bíblico, aunque solo se conozcan parcialmente o muchos de sus secretos se hayan perdido, se convierte de esta manera en un enunciado performativo, una reconstitución de un orden original. Como dijo Judá ben Shělomo Al-Harizi en su Taḩkěmoní, con lo que queda de la lengua sagrada "podemos hacer verdaderas maravillas" (1.4).

\section{REFERENCIAS}

ADAms, James Noel. 2003. Bilingualism and the Latin Language. Cambridge: Cambridge University Press.

Alfonso, Esperanza. 2004. "The Uses of Exile in Poetic Discourse: Some Examples from Medieval Hebrew Literature». En Renewing the Past, Reconfiguring Jewish Culture, editado por Ross Brann y Adam Stucliffe, 31-49. Philadelphia: University of Pennsilvania Press. 
AL-Harizi, Judá ben Shělomo. 2018. Las asambleas de los sabios (Tahkèmoní). Edición y traducción de Carlos del Valle Rodríguez. Murcia: Universidad de Murcia.

Alighieri, Dante. 2018. De vulgari eloquentia. Edición bilingüe de Raffaele Pinto. Madrid: Cátedra.

Alony, Nehemías. 1995. El resurgimiento de la lengua bebrea en Al-Ándalus. Traducción de Antonio Peral y Carlos del Valle. Madrid: Aben Ezra.

Álvaro De Córdoba. 1996. "Indiculus luminosus». En Álvaro de Córdoba, y la polémica contra el Islam: el Indiculus luminosus, editado por Feliciano Delgado León, 75-185. Córdoba: Publicaciones Obra Social y Cultural Cajasur.

Armstrong, John A. 1982. Nations before Nationalism. Chapel Hill: University of North Carolina Press.

Benavente Robles, Santiaga. 1986. Tešubot de los discípuos de Menahem contra Dunaš. Granada: Universidad de Granada.

Classen, Albrecht, ed. 2016. Multilingualism in the Middle Ages and Early Modern Age. Communication and Miscommunication in the Premodern World. Berlín: De Gruyter.

CoHen, Mark. 2000. «Sociability and the Concept of Galut in Jewish-Muslim Relations in the Middle Ages». En Judaism and Islam: Boundaries, Communication, and Interaction: Essays in Honor of William M. Brinner, editado por Benjamin H. Hary et al., 37-51. Leiden: Brill.

Dadour, Ali A. Hassan. 1993. El tema del exilio en la poesía hispano-árabe tras la caída del califato. Tesis doctoral. Universidad Complutense de Madrid.

Domínguez, César. "Medieval Transnationalism?». En Literary Transnationalism(s), editado por Dagmar Vandebosch y Theo D'Haen, 15-27. Leiden/Boston: Brill/ Rodopi, 2018.

Elinson, Alexander E. 2009. Looking Back at al-Andalus: The Poetics of Loss and Nostalgia in Medieval Arabic and Hebrew Literature. Leiden/Boston: Brill.

Entwistle, W. J. 1937. "Cancionero de Baena, 226, v. 2". Hispanic Review 5 (1): 78-79.

Eulogio DE CóRdoBA. 1973. «Memoriale Sanctorum». En Corpus scriptorum mozarabicorum, editado por Juan Gil, 363-459. Madrid: Consejo Superior de Investigaciones Científicas.

'EzRÁ, Mošeh ibn. 1935. Shire ha-hol. Editado por Hayyim Brody. Berlín: Schocken.

'Ezrá, Mošeh ibn. 1986. Kitab al-Muhadara wal-Mudakara. Editado y traducido por Montserrat Abumalham Mas. Madrid: CSIC.

FERRANDO, Ignacio. 2000. "The Arabic Language among the Mozarabs of Toledo". En Contributions to the Sociology of Language: Arabic as a Minority Language, editado por Jonathan Owens, 45-63. Berlín: Mouton.

FORSTER, Leonard. 1970. The Poet's Tongues: Multilingualism in Literature. Londres: Cambridge University Press.

Gallego García, María Ángeles. 2003. "The Languages of Medieval Iberia and Their Religious Dimension». Medieval Encounters 9 (1): 107-139.

Gallego García, María Ángeles. 2006. El judeo-árabe medieval. Berna: Peter Lang. 
Gallego García, María Ángeles. 2010. "The Impact of Arabic Diglossia among the Muslims, Jews and Christians of al-Andalus». En A Comparative History of Literatures in the Iberian Peninsula, editado por Fernando Cabo Aseguinolaza, Anxo Abuín González y César Domínguez, 1: 351-365. Ámsterdam: John Benjamins.

GEARY, Patrick J. 1983. "Ethnic Identity as a Situational Construct in the Early Middle Ages». MAGW 113: 15-26.

GIL, Juan. 1971 "Apuntes sobre la morfología de Álvaro de Córdoba». Habis 2: 199-206.

GuTiÉRREZ GARCíA, Santiago. 2015. «El multilingüismo en la lírica trovadoresca gallegoportuguesa, entre la barbarolexis y la clerecía». Zeitschrift für romanische Philologie 131 (3): 690-713.

HA-Levi, Yehudá. 1910. El Cuzary. Traducido por Yehudá Abentibbon y Jacob Abendana. Madrid: Victoriano Suárez.

HämeEn-AntTila, Jaakko. 2002. Maqama: A History of a Genre. Wiesbaden: Harrasowitz.

JuAn MANUEl. 1971. El Conde Lucanor o Libro de los enxiemplos del Conde Lucanor et de Petronio. Editado por José Manuel Blecua. Madrid: Castalia.

HANLON, David. 1997. "A Sociolinguistic View of "hazl" in the Andalusian Arabic "muwashshah"”. Bulletin of the School of Oriental and African Studies 60 (1): 35-46.

Katzew, Jan D. 1984. "Moses ibn Ezra and Judah ha-Levi: Their Philosophies in Response to Exile». Hebrew Union College Annual 55: 179-195.

KleInHenZ, Christopher y Keith BusBy, eds. 2010. Medieval Multilingualism. The Francophone World and its Neighbours. Turnhout: Brepols.

KrotKoff, George. 1974. "The Arabic Line in the Cancionero de Baena». Hispanic Review 42 (4): 427-429.

LAPIEDRA GutiéRrez, Eva. 1997. Cómo los musulmanes llamaban a los cristianos bispánicos. Alicante: Instituto de Cultura «Juan Gil-Albert».

LÉGLU, Catherine E. 2010. Multilingualism and Mother Tongue in Medieval French, Occitan, and Catalan Narratives. University Park: Penn State University Press.

MOnRoE, James T. 1970. The Shu'übiyya in al-Andalus: the risäla of Ibn Garcia and five refutations. Berkeley: University of California Press.

Navarro Peiro, Ángeles. 1995. "El tema del exilio en la poesía de Mošé ibn 'Ezrá". Miscelánea de Estudios Árabes y Hebraicos 44: 47-59.

Navarro Peiro, Ángeles. 2001. "Mošé ibn 'Ezrá: El poema de los dos exilios». Sefarad 61 (2): 381-393.

NykL, A. R. 1938. "Cancionero de Baena, 226, v. 2". Hispanic Review 6 (4): 349-350.

NYKL, A. R. 1942. "Arabic Phrases in El conde Lucanon. Hispanic Review 10 (1): $12-17$.

Orfali, Moisés. 1995. «El significado de Jerusalén y Sión en la tradición judía medieval». Anuario de Historia de la Iglesia 4: 183-198.

Rubiera Mata, María Jesús. 1992. Literatura hispanoárabe. Madrid: Fundación Mapfre. 
RuIz, Juan. 2006. Libro de buen amor. Editado por José Manuel Blecua. Madrid: Cátedra.

SÁENZ BADillos, Ángel. 1980. «El 'Anaq, poema lingüístico de Šělomoh ibn Gabirol». Miscelánea de Estudios Árabes y Hebraicos 29 (2): 5-29.

SÁenz BADILlos, Ángel. 1988. Historia de la lengua hebrea. Sabadell: AUSA.

SÁENZ BADILlos, Ángel. 1990. "Diez moaxajas hebreas de Mošeh lbn 'Ezra': traducción y comentario". Miscelánea de Estudios Árabes y Hebraicos 39 (2): 47-69.

SÁncheZ-Ostiz, Álvaro et al., eds. 2007. De Grecia a Roma y de Roma a Grecia: un camino de ida y vuelta. Pamplona: EUNSA.

SCHIPPERS, Arie. 1994. Spanish Hebrew Poetry \& the Arabic Literary Tradition: Arabic Themes in Hebrew Andalusian Poetry. Leiden: E. J. Brill.

SMITH, Anthony D. 1986. The Ethnic Origins of Nations. Londres: Blackwell.

TAVANI, Giuseppe. 1981. Il mistilinguismo letterario romanzo tra XII e XVI secolo. L'Aquila: Japadre.

Terés, Elías. 1956. "Algunos ejemplos de emulación poética en al-Andalus». En Homenaje a Millás Vallicrosa, 2: 445-466. Barcelona: Consejo Superior de Investigaciones Científicas.

TORres Guerra, José Bernardino, ed. 2011. Vtroque sermone nostro. Bilingüismo social y literario en el imperio de Roma. Pamplona: EUNSA.

VIDAL DE BESAlú, Raimon. 1972. The "Razos de trobar" of Raimon Vidal and Associated Texts. Editado por John Marshall. Oxford: Oxford University Press.

Wahnón Bensusan, Sultana. 1995. "The Condition of Exile in Twelfth-Century Judaic Poetics". En Inequality and Difference in Hispanic and Latin American Cultures, editado por Robert McGuirk y Mark Millington, 33-50. Lewiston: Queenston y Lampeter: Edwin Miller.

WAHNón BENSUSAN, Sultana. 1998. "Humanismo y pensamiento judío: sobre la poética de Mošé Ibn 'Ezra”. En Judaísmo y límites de la modernidad, editado por M. Beltrán, J. M. Mardones y Reyes Mate, 159-174. Barcelona: Riopiedras.

WAHNÓn BENSUSAN, Sultana. 2009. "El ideal cosmopolita: claves históricas y culturales». En Las lenguas extranjeras como vehículo de comunicación intercultural, editado por Julián Jiménez Heffernan y María J. López-Pedraza Gómez, 85127. Madrid: Ministerio de Educación, Cultura y Deporte, Subdirección General de Información y Publicaciones.

WassersteIn, David. 1991. "The Language Situation in al-Andalus». En Studies on the Muwashshah and the Kharja, editado por Alan Jones y Richard Hitchcock, 1-15. Oxford: Oxford University Press.

WeINREICH, Uriel. [1953] 1974. Lenguas en contacto. Descubrimientos y problemas. Traducido por Francisco Rivera. Caracas: Ediciones de la Biblioteca de la Universidad Central de Venezuela.

Zumthor, Paul. 1960. "Un problème d'esthétique médiévale : l'utilisation poétique du bilinguisme». Le Moyen Âge 4: 561-594. 
